\title{
Superior vena cava thrombosis and dilated cardiomyopathy as initial presentations of Behcet's disease
}

\author{
Ahmed M. Elzanaty ${ }^{1 *}$, Mohammed T. Awad', Ashu Acharaya', Ebrahim Sabbagh², Eman Elsheikh ${ }^{3}$ and \\ Moshrik AbdAlamir ${ }^{2}$
}

\begin{abstract}
Background: Bechet's disease (BD) is a relatively rare disease that causes recurrent oral and genital ulcers in addition to a variety of systemic manifestations. Concomitant superior-vena-cava (SVC) thrombosis and cardiac involvement with dilated cardiomyopathy (DCM) as initial presentations for BD is considered rare.

Case presentation: A 32-year-old-man presenting with intractable headaches and dyspnea. He was later diagnosed with SVC thrombosis and DCM. A diagnosis of BD was made after detailed history-taking.

Conclusions: Cardiovascular manifisations can be the initial presentation of BD. We aim to highlight the importance of early clinical recognition of BD as a cause of DCM and SVC thrombosis.
\end{abstract}

Keywords: SVC thrombosis, Dilated cardiomyopathy, Behcet's disease

\section{Introduction}

$\mathrm{BD}$ is a rare disease, affecting 1 per 15,000 to 1 per 500 , 000 people in North America and European countries [1]. It is known to cause recurrent oral and genital ulcers alongside a wide variety of systemic presentation mostly related to vasculitis. Cardiac involvement, on the other hand, is rare in BD affecting from 7 to $31 \%$ of patients with the disease [2]. Cardiac involvement includes inflammation of all cardiac layers from the pericardium to myocardium, LV thrombus formation, endomyocardial fibrosis, and coronary arteritis [3-5].

\section{Case report}

A 32-year-old caucasian man with a past medical history of bronchial asthma presenting with generalized fatigue, orthopnea with intermittent fevers as well as recurrent

\footnotetext{
* Correspondence: Ahmedm.elzanaty@gmail.com

${ }^{1}$ Internal Medicine Departement, University of Toledo, 3000 Arlington Avenue, Toledo, $\mathrm{OH} 43614$, USA

Full list of author information is available at the end of the article
}

sore throat for 9 months. Those symptoms triggered multiple emergency room visits and for which he received the diagnosis of recurrent viral upper respiratory tract infection (URTI). The patient started to develop intractable headaches with facial and chest wall swelling for 2 weeks prior to his admission to our hospital. Physical exam showed a positive Pemberton sign (facial plethora when raising the upper extremities). Lumbar puncture was performed which revealed a significantly elevated opening pressure of $36 \mathrm{mmH}_{2} \mathrm{O}$. With the suspicion of superior vena cava syndrome in mind, the patient subsequently underwent $\mathrm{CT}$ angiogram that confirmed the presence of SVC thrombosis that extended to involve the brachiocephalic vein (Fig. 1). Extensive investigations including autoimmune, vasculitis, as well as thrombophilia workup were done and they were within normal. The patient's BNP, troponin I, and creatine kinase were also normal. The only lab abnormalities of significance were the raised ESR of $68 \mathrm{~mm} /$, CRP of $7.3 \mathrm{mg} / \mathrm{dl}$, anda reactive thrombocytosis with platelets of $506 \times 10 \mathrm{E} 9 / \mathrm{L}$. The patient 


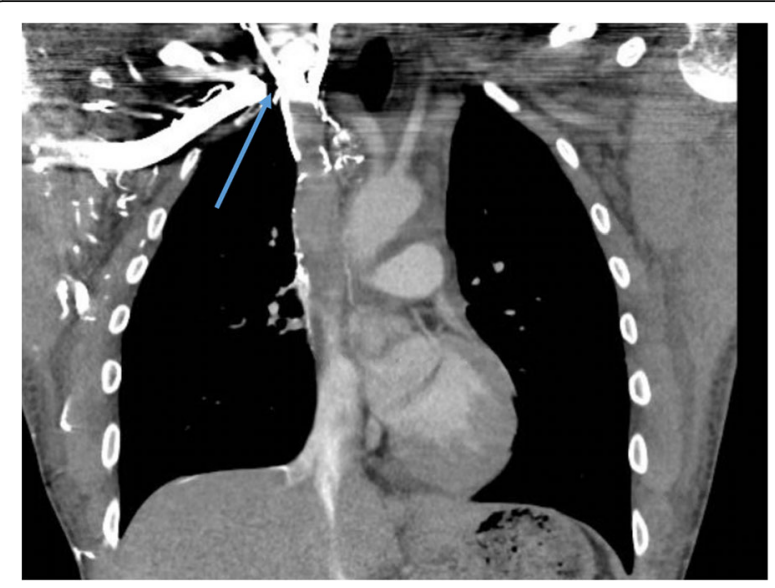

Fig. 1 CT chest on admission showed SVC thrombus that extended to involve the brachiocephalic vein

continued to have orthopnea despite initiation of heparin infusion and improvement of his SVC thrombosis symptoms for which a transthoracic echocardiogram was done which revealed global hypokinesia with ejection fraction (EF) of $20-25 \%$.

Upon further detailed history taking, the patient reported having mouth ulcers that used to erupt whenever he had a sore throat (Fig. 2). He also reported unusual papules in his legs that matched the description of

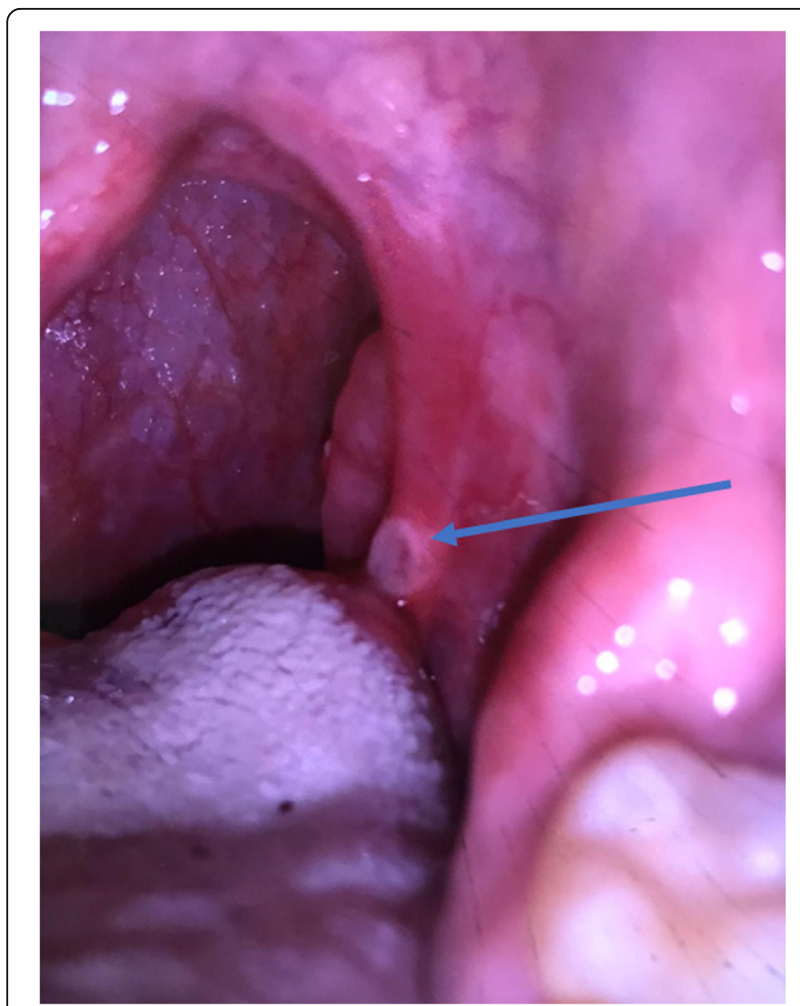

Fig. 2 Self-captured photo for prior oral ulcer pseudofolliculitis (Fig. 3). Furthermore, he reported a family history of BD in one of his distant family members. Pathergy test was not formally done, but there were skin reactions reported after blood draws. A diagnosis of BD was made after fulfilling the diagnostic criteria of the International Study Group for BD with recurrent oral ulcers alongside skin lesions of pseudofolliculitis and positive pathergy test. The patient was then started on methylprednisone.

The patient was also started on sacubitril/valsartan, carvedilol, aspirin, and atorvastatin given his new heart failure with reduced ejection fraction. He later underwent myocardium perfusion imaging that showed low normal EF with no reversible ischemia making the diagnosis of coronary artery disease with ischemic cardiomyopathy less likely. Coronary angiography wasn't pursued given low suspicion for coronary artery disease and ongoing SVC thrombosis. Aspirin was also discontinued given the same reason. Three days after the initiation of steroids, the patient continued to report significant improvement in his symptoms, he eventually underwent cardiac MRI that revealed an improvement of his EF to $52 \%$ with no evidence of myocardial scarring or fibrosis (Fig. 4). The patient was discharged on oral prednisone, lisinopril, metoprolol succinate, and warfarin. The patient was in good condition upon discharge with followup with rheumatology, vascular surgery, and cardiology for his BD, SVC thrombosis, and heart failure with recovered ejection fraction.

On outpatient follow up, the patient remained to do well. His steroids were gradually tapered and he was started on colchicine after which he continued to be symptom-free.

\section{Case discussion}

$\mathrm{BD}$ is a chronic relapsing autoimmune disorder of unknown etiology that is rare especially outside of the Silkroad area [6]. It is mostly diagnosed clinically, and that is why a thorough history and physical exam are needed to uncover it. A diagnosis is made when a patient is found to have recurrent oral ulcers alongside two of the following; recurrent genital aphthae, eye lesions like anterior or posterior uveitis, skin lesions like pseudofolliculitis, and a positive pathergy test [7].

BD's main pathophysiology is through vascular involvement [8], in the form of vasculitis, thromboembolic complication, as well as pseudoaneurysm [9]. Venous involvement is believed to be secondary to endothelial inflammation leading to eventual thrombosis [10]. Vascular involvement can be effectively managed with immunosuppression with anticoagulation being preserved if thrombotic events occurred [11]. In our case, the main symptom that prompted the patient to seek medical attention was the protracted headache, which 


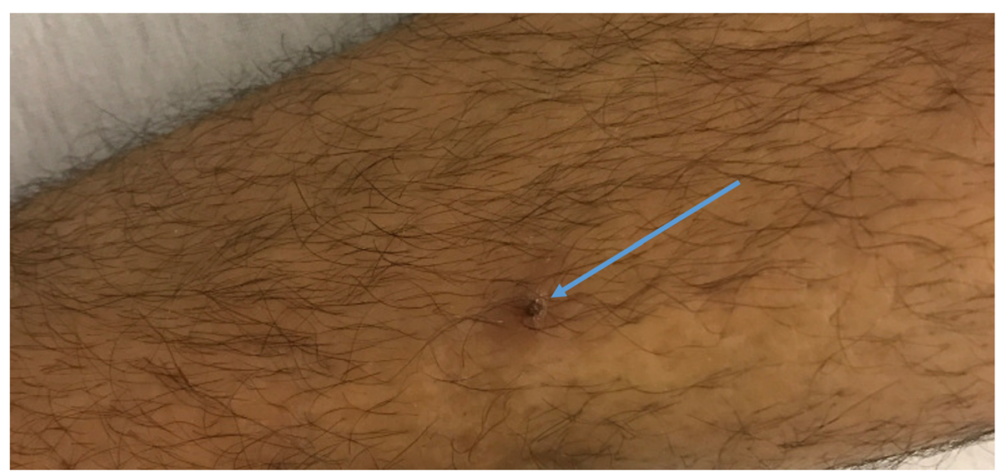

Fig. 3 Photo of psudo-folliculitis lesion

was later attributed to increased intracranial pressure secondary to SVC thrombosis. SVC involvement in BD is well known, Koc et al. in his review of vascular involvement in $\mathrm{BD}$, report it as the 3rd most common venous site involvement [12]. The patient continued to have orthopnea and shortness of breath despite SVC thrombosis treatment for which a $2 \mathrm{D}$ echo was done that lead to the incidental discovery of DCM.

Cardiac involvement in $\mathrm{BD}$ is rare but reported in the medical literature $[13,14]$. The cardiac presentation includes inflammation of one or all of cardiac layers, endomyocardial fibrosis, coronary arteritis with subsequent coronary artery disease, intracardiac thrombus, conduction system disturbances, and valvular disease [15]. Patients who have underlying cardiac complications have a poor prognosis with mortality reaching $20 \%$ [15]. However, to our knowledge the association of non-ischemic DCM with BD has been rarely reported with less than a handful of reported cases being found in our search
[16-18]. In our case, the patient was started early on steroids with a rapid and remarkable recovery of the symptoms as well the myocardium function over the course of 3 days, with symptoms as well as ejection fraction recovering from $25 \%$ on $2 \mathrm{D}$ echo to $52 \%$ on Cardiac MRI. Our case is different from prior case reports as it might point to the fact that early steroid use can rapidly convert heart failure with reduced ejection fraction to heart failure with recovered EF.

In our case, if an early emphasis was made on history taking as well as a detailed physical exam to uncover the recurrent oral ulcers alongside the skin lesions instead of initially fixating on the diagnosis of viralURTI would have saved the patient recurrent ER visits.

\section{Conclusion}

Recognizing the rare, but possibly grave, cardiac manifestation of $\mathrm{BD}$ including dilated non-ischemic cardiomyopathy

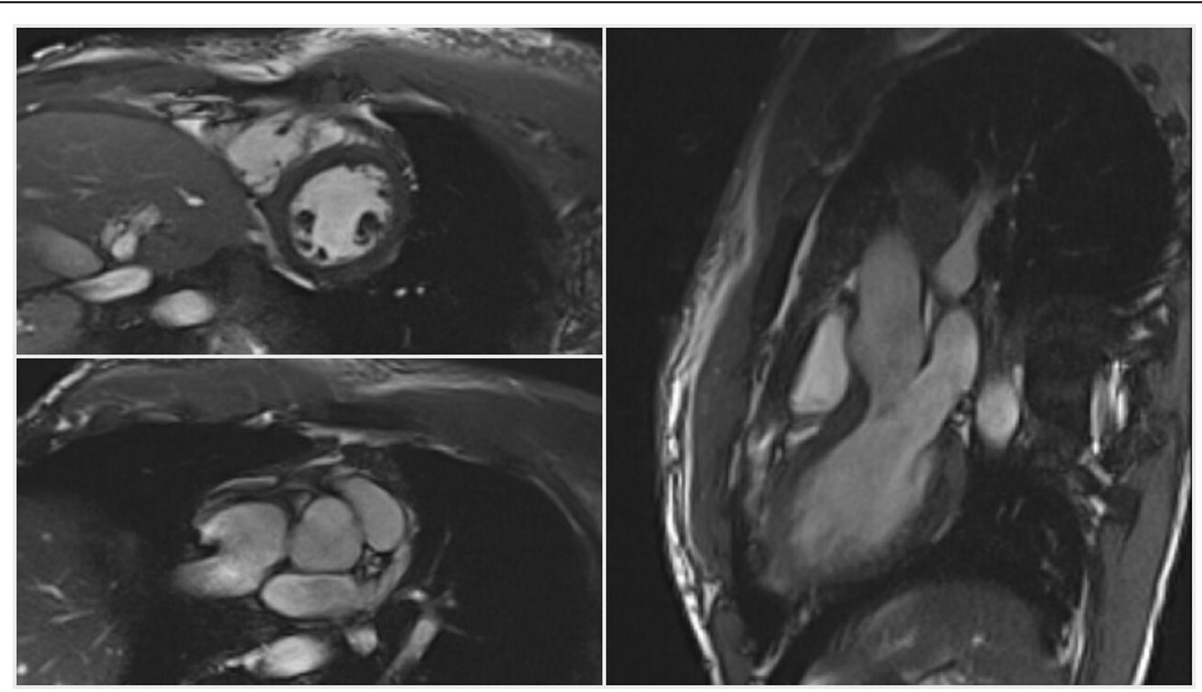

Fig. 4 Multiple Sections through CMR revealing normal myocardium with no evidence of endomyocardial fibrosis or scarring 
is essential as it might aid in making the diagnosis and avoid the burden of over-testing.

\section{Learning objectives}

1. Recognize cardiovascular manifestation of $\mathrm{BD}$ including DCM and SVC thrombosis.

2. Emphasis the role of history taking in cases of unexplained cardiomyopathy to avoid the burden of over-testing.

\section{Abbreviations}

DCM: Dilated cardiomyopathy; BD: Behcet's disease; SVC: Superior vena cava

\section{Acknowledgments}

Not applicable.

\section{Disclosures}

No conflicts of interest or relationship with the industry to disclose by any of the authors.

\section{Authors' contributions}

All authors read and approved the final manuscript. All authors contributed equally to this work.

\section{Funding}

Not applicable.

Availability of data and materials

Not applicable.

Ethics approval and consent to participate

Not applicable.

\section{Consent for publication}

Not applicable.

\section{Competing interests}

The authors declare that they have no competing interests.

\section{Author details}

${ }^{1}$ Internal Medicine Departement, University of Toledo, 3000 Arlington Avenue, Toledo, $\mathrm{OH} 43614$, USA. ${ }^{2}$ Cardiology Departement, University of Toledo, Toledo, Ohio, USA. ${ }^{3}$ Cardiology Departement, Tanta University Hospital, Tanta, Egypt.

Received: 25 April 2020 Accepted: 10 June 2020

Published online: 06 July 2020

\section{References}

1. Calamia KT, Wilson FC, Icen M, Crowson CS, Gabriel SE, Kremers HM. Epidemiology and clinical characteristics of Behcet's disease in the US: a population-based study. Arthritis Rheum. 2009;61(5):600-4.

2. Roguin A, Edoute Y, Milo S, Shtiwi S, Markiewicz W, Reisner SA. A fatal case of Behcet's disease associated with multiple cardiovascular lesions. Int J Cardiol. 1997:59(3):267-73.

3. Gurgun C, Ercan E, Ceyhan C, Yavuzgil O, Zoghi M, Aksu K, et al. Cardiovascular involvement in Behcet's disease. Jpn Heart J. 2002;43(4):389-98.

4. Wang H, Guo X, Tian Z, Liu Y, Wang Q, Li M, et al. Intracardiac thrombus in patients with Behcet's disease: clinical correlates, imaging features, and outcome: a retrospective, single-center experience. Clin Rheumatol. 2016; 35(10):2501-7

5. Pu L, Li R, Xie J, Yang Y, Liu G, Wang Y, et al. Characteristic echocardiographic manifestations of Behcet's disease. Ultrasound Med Biol. 2018:44(4):825-30.

6. Yazici H, Fresko I, Yurdakul S. Behcet's syndrome: disease manifestations, management, and advances in treatment. Nat Clin Pract Rheumatol. 2007; 3(3):148-55
7. International Study Group for Behcet's Disease. Criteria for diagnosis of Behcet's disease. Lancet (London, England). 1990;335(8697):1078-80.

8. Sarica-Kucukoglu R, Akdag-Kose A, Kayabal IM, Yazganoglu KD, Disci R, Erzengin D, et al. Vascular involvement in Behcet's disease: a retrospective analysis of 2319 cases. Int J Dermatol. 2006;45(8):919-21.

9. Mouine N, Bennani R, Amri R. A giant left ventricular pseudoaneurysm in Behcet's disease: a case report. Cardiol Young. 2014;24(2):382-3.

10. Barnes CG. Treatment of Behcet's syndrome. Rheumatology (Oxford). 2006; 45(3):245-7.

11. Tayer-Shifman OE, Seyahi E, Nowatzky J, Ben-Chetrit E. Major vessel thrombosis in Behçet's disease: the dilemma of anticoagulant therapy - the approach of rheumatologists from different countries. Clin Exp Rheumatol. 2012;30(5):735-40

12. Koc Y, Gullu I, Akpek G, Akpolat T, Kansu E, Kiraz S, et al. Vascular involvement in Behcet's disease. J Rheumatol. 1992:19(3):402-10.

13. Cocco G, Gasparyan AY. Behcet's disease: an insight from a Cardiologist's point of view. Open Cardiovasc Med J. 2010;4:63-70.

14. Morelli S, Perrone C, Ferrante L, Sgreccia A, Priori R, Voci P, et al. Cardiac involvement in Behcet's disease. Cardiology. 1997;88(6):513-7.

15. Geri G, Wechsler B, Thi Huong du L, Isnard R, Piette JC, Amoura Z, et al. Spectrum of cardiac lesions in Behcet disease: a series of 52 patients and review of the literature. Medicine. 2012;91(1):25-34.

16. Scheuble A, Belliard O, Robinet S, Boccara F, Bardet J, Cohen A. Symptomatic left ventricular dysfunction and Behcet disease. Report of 2 cases. Arch Mal Coeur Vaiss. 2003;96(2):131-4.

17. Kaatz M, Gornig M, Bocker T, Zouboulis CC, Wollina U. Late manifestation of a fatal Behcet's disease with cardiac involvement and lethal outcome. Deutsche Medizinische Wochenschrift (1946). 1998;123(8):217-22.

18. Al Izzi M, El Bur M, Arif M. A diagnosis not to be missed: Behcet's disease as a cause of dilated cardiomyopathy in a young Arab male patient. Int J Rheum Dis. 2010;13(1):97-9.

\section{Publisher's Note}

Springer Nature remains neutral with regard to jurisdictional claims in published maps and institutional affiliations.
Ready to submit your research? Choose BMC and benefit from:

- fast, convenient online submission

- thorough peer review by experienced researchers in your field

- rapid publication on acceptance

- support for research data, including large and complex data types

- gold Open Access which fosters wider collaboration and increased citations

- maximum visibility for your research: over $100 \mathrm{M}$ website views per year

At $\mathrm{BMC}$, research is always in progress.

Learn more biomedcentral.com/submissions 